\title{
O ENSINO DE QUÍMICA QUÂNTICA E O COMPUTADOR NA PERSPECTIVA DE PROJETOS
}

\author{
Agnaldo Arroio, Káthia M. Honório, Karen C. Weber, Paula Homem-de-Mello e Albérico B. F. da Silva* \\ Departamento de Química e Física Molecular, Instituto de Química de São Carlos, Universidade de São Paulo, \\ CP 780, 13560-970 São Carlos - SP
}

Recebido em 22/1/04; aceito em 6/8/04; publicado na web em 14/1/05

\begin{abstract}
THE TEACHING OF QUANTUM CHEMISTRY AND THE COMPUTER FROM THE PERSPECTIVE PROJECTS. This paper aims to discuss and reflect about the use of computers in the teaching of Quantum Chemistry. A course on Computational Quantum Chemistry concentrating on Medicinal Chemistry projects was developed for undergraduate and graduate students. The results showed that students got more motivated and involved when there is an articulation between theory and practice. This work presents an alternative way to teach Theoretical Chemistry using projects.
\end{abstract}

Keywords: computer; projects; quantum chemistry teaching.

\section{INTRODUÇÃO}

A mecânica quântica é considerada uma das maiores realizações intelectuais do século XX e tem sido a base conceitual que permitiu o entendimento da química de uma maneira bem mais profunda do que aquela existente antes dos anos 20, época em que foram lançadas as bases da teoria quântica. $\mathrm{O}$ impacto dessa teoria na química pode ser verificado pelas suas implicações práticas em ramos diversos como espectroscopia, microscopia eletrônica, modelagem molecular, entre outras.

Especialmente no que se refere a modelos moleculares, o papel desempenhado pela mecânica quântica é, juntamente com a termodinâmica estatística, de integração da linguagem e de conceitos químicos, permitindo a interpretação e a racionalização de propriedades macroscópicas com fundamentos em nível atômicomolecular ${ }^{1}$. Diante dessas considerações, fica evidente a importância da química quântica nos currículos de química em suas diferentes modalidades, desde a licenciatura até a pós-graduação, uma vez que a aprendizagem dos conceitos que a compõe leva a uma compreensão mais detalhada de diversos fenômenos químicos e, em especial, daqueles que só podem ser considerados mediante a utilização dos formalismos inerentes a ela.

Contudo, uma característica da química quântica, que a torna particularmente complexa para os alunos, é a necessidade de se compreender conceitos abstratos que são, em grande parte, não-intuitivos. Além disso, deficiências em disciplinas básicas como Álgebra Linear, Geometria Analítica e Cálculo Diferencial e Integral tornam os conteúdos relacionados à teoria quântica de difícil compreensão. Entretanto, o problema mais grave parece ser o fato de que, em geral, não se discute a relação desses conteúdos com as suas várias aplicações nas diferentes áreas da química. Dessa forma, muitos alunos dificilmente conseguirão estabelecer relações entre a química quântica e os fenômenos da vida cotidiana, por se tratarem de conceitos complexos e difíceis de visualizar, principalmente por serem trabalhados apenas nas dimensões verbais e textuais. A gravidade deste problema assume dimensões mais sérias quando se pensa que esses alunos serão os professores que terão de ensinar conceitos relacionados à estrutura atômica aos alunos de Ensino Médio.

\footnotetext{
*e-mail: alberico@iqsc.usp.br
}

Neste contexto, e sendo o computador a ferramenta de trabalho nas pesquisas em química teórica, uma estratégia envolvendo este recurso parece ser a escolha óbvia quando se procura aumentar o interesse dos alunos e facilitar a compreensão dos conceitos químicoquânticos. Paralelamente à expansão e popularização dos recursos computacionais, tanto no avanço de seu potencial de operação quanto na diversidade de uso, Morgon ${ }^{2}$ demonstra como a química teórica tem se expandido nas últimas décadas no Brasil, evidenciando a necessidade de se buscar alternativas para a melhoria do ensino com a finalidade de fundamentar os estudantes no domínio desta área.

Considerando estes pressupostos, surge a proposição de incorporar o computador no ensino de química quântica, uma vez que esse recurso permite que os alunos explorem, entre outros, os aspectos conformacionais das moléculas e, eventualmente, as propriedades que dependem da disposição dos átomos e do arranjo tridimensional das moléculas, de acordo com os modelos vigentes. Além de auxiliar na assimilação destes conteúdos, a aplicação da química computacional a problemas de interesse industrial pode ser inserida com a finalidade de contextualizar o ensino de química quântica, podendo ainda despertar o interesse do aluno para atividades de pesquisa na área.

A evolução dos computadores ("hardware") contribuiu muito para o desenvolvimento de programas educacionais e isto se deu, aproximadamente, ao longo de 18 anos. Observando a utilização de programas educacionais nos últimos anos ${ }^{3}$, podem ser verificadas mudanças significativas nos objetivos de utilização destes programas: de simples cálculos computacionais e tutoriais (pouco interativos) às simulações e bases de dados, modelagem e/ou simulações com previsão, que permitem boa interação aluno-conhecimento ${ }^{4}$. Desta forma, pode-se constatar algumas mudanças resultantes da utilização de computadores no ensino, como ilustra a Tabela 1.

A concepção de utilização do computador que norteia este trabalho é de que este recurso cria condições de aprendizagem por meio do desenvolvimento de atividades orientadas pelo professor, que assume um papel de mediador entre o aluno e todo o potencial que pode ser extraído dos computadores.

Outro aspecto deste trabalho é a utilização de projetos como facilitadores da aprendizagem. Esta abordagem tem sido amplamente explorada desde a década de 20, com Dewey ${ }^{5}$ e recentemente com Hernández ${ }^{6}$, inserida em diferentes métodos tradicionais na educação. "Os projetos de trabalho contribuem para uma resignificação 
Tabela 1. Mudanças apresentadas no ensino com a utilização de computadores

\begin{tabular}{ll}
\hline Sociedade Industrial & Sociedade Informatizada \\
\hline $\begin{array}{l}\text { Todos os alunos devem receber } \\
\text { a mesma informação (e ao } \\
\text { mesmo tempo). }\end{array}$ & $\begin{array}{l}\text { Capacitações diferentes; os } \\
\text { alunos têm estilos individuais } \\
\text { de aprendizagem. }\end{array}$ \\
\hline Memorização da informação. & $\begin{array}{l}\text { Sem memorização: saber } \\
\text { navegar com eficiência em } \\
\text { CD-ROMs e bancos de } \\
\text { dados on-line. }\end{array}$ \\
\hline Ênfase na transmissão do & $\begin{array}{l}\text { Ênfase na aprendizagem de } \\
\text { interpretação e julgamento. }\end{array}$ \\
\hline conhecimento. & $\begin{array}{l}\text { Avaliação através de dossiês de } \\
\text { trabalhos (portfólios). }\end{array}$ \\
testes de conhecimeña através de provas e & O professor atua como \\
\hline $\begin{array}{l}\text { O professor é o "dono" e o } \\
\text { principal entregador do }\end{array}$ & mediador do conhecimento. \\
conhecimento. &
\end{tabular}

dos espaços de aprendizagem de tal forma que eles se voltem para a formação de sujeitos ativos, reflexivos, atuantes e participantes".

Assim, na forma de um curso de extensão ministrado a alunos de graduação e pós-graduação, propusemos uma maneira de introduzir conceitos de química quântica visando o entendimento do planejamento de fármacos. Os conceitos estudados foram relacionados a propriedades estruturais e eletrônicas que estão envolvidas nos mecanismos de compostos com atividade farmacológica. Esta foi uma forma encontrada para contextualizar os conceitos, de maneira que fossem relacionados com suas aplicações. Os problemas propostos foram trabalhados na forma de desenvolvimento de projetos, utilizando recursos computacionais para o cálculo de propriedades possivelmente importantes para o estudo desenvolvido.

\section{METODOLOGIA}

Conforme explicado anteriormente, a escolha dos projetos foi feita a partir da problematização de um tema geral sobre a aplicação da química quântica: o planejamento de fármacos. Os alunos formaram grupos e coletivamente definiram, juntamente com o professor, o que seria interessante para ser pesquisado e aprendido. Ao professor cabia estimular e motivar os grupos por meio de questões relevantes, para que a busca de soluções pudesse gerar aprendizagem.

Após a escolha do tema surge o problema de como desenvolver os projetos. Neste momento foi necessário adquirir mais conhecimentos a respeito da teoria, bem como das ferramentas computacionais disponíveis.

Os fundamentos da mecânica quântica foram tratados de maneira sucinta, ressaltando o papel de temas como partícula na caixa, rotor rígido e oscilador harmônico, sem muito aprofundamento quanto ao formalismo matemático, uma vez que a finalidade não era treinar os alunos na resolução de exercícios ou fazê-los decorar teoremas, mas sim demonstrar como esses conteúdos são introduzidos em química e quais são as suas finalidades ${ }^{1,7,8}$.

Seguiu-se, então, uma introdução aos métodos de resolução da Equação de Schrödinger. As teorias que explicam as ligações químicas (Teoria de Ligação de Valência e Teoria de Orbitais Moleculares), foram tratadas para o entendimento mais detalhado da estrutura eletrônica de moléculas ${ }^{8}$. Por fim, foram estudados os aspectos históricos do desenvolvimento da química computacional, os métodos teóricos utilizados para otimização de geometrias, análises conforma- cionais e cálculo de propriedades, bem como as potencialidades e limitações de cada método ${ }^{8,9}$. O programa referente ao planejamento de fármacos pode ser resumido nos seguintes tópicos:

1. Conceitos básicos em modelagem molecular; discussão sobre métodos teóricos (semi-empíricos, ab initio, dinâmica molecular e Monte Carlo $)^{9-11}$.

2. Parâmetros moleculares utilizados no estudo da relação estrutura-atividade (SAR) (parâmetros eletrônicos, estéricos, hidrofóbicos e topológicos) ${ }^{12}$.

3. Estudo da relação quantitativa entre estrutura-atividade (QSAR); métodos de quimiometria aplicados à QSAR: PCA (análise de componentes principais), HCA (análise hierárquica de agrupamentos), SIMCA (modelos independentes de similaridade utilizando componentes principais), KNN (método do K-ésimo vizinho mais próximo), PCR (regressão por componentes principais), PLS (regressão por mínimos quadrados parciais) ${ }^{13-15}$.

Os alunos efetuaram, então, cálculos de propriedades eletrônicas e estruturais utilizando os seguintes programas computacionais disponíveis no Grupo de Química Quântica do IQSC-USP: HyperChem 4.5 ${ }^{16}$, Spartan 5.0 ${ }^{17}$, Ampac $6.5^{18}$ e Gaussian $98^{19}$. Inicialmente, os programas foram utilizados para resolução de exercícios propostos. A seguir, os alunos foram incentivados a procurar na literatura um sistema de interesse, ou seja, um fármaco, sua aplicação e, possivelmente, o receptor biológico. A possibilidade de estudo de cada sistema foi avaliada em conjunto com o professor, possibilitando uma maior discussão das possibilidades computacionais de cálculo e da busca de relações entre as propriedades físico-químicas, estruturais e eletrônicas dos compostos estudados e suas atividades biológicas.

Cada grupo apresentou ao final do curso um seminário, destacando a relevância do fármaco escolhido e a sua utilização, os procedimentos de cálculo adotados, os resultados obtidos, as conclusões e perspectivas, bem como as experiências e dificuldades que vivenciaram no desenvolvimento dos projetos.

A avaliação aconteceu em três dimensões: durante a execução dos projetos, durante a apresentação dos mesmos e por meio de um questionário. As avaliações ocorreram no desenvolver do projeto de forma contínua, considerando a participação de todos os envolvidos com um olhar direcionado aos objetivos propostos no início para cada um e seus respectivos desempenhos. Já no questionário, os alunos deveriam avaliar seu próprio desempenho, o curso como um todo e a participação dos professores.

\section{UM ESTUDO DE CASO}

Será apresentado a seguir um dos projetos desenvolvidos pelos alunos participantes do curso. O grupo em questão realizou inicialmente uma pesquisa bibliográfica em busca de compostos de seu interesse. Neste caso, os compostos escolhidos pelo grupo foram a Fluoxetina e a Zimeldina (ver Figura 1), princípios ativos do Prozac e do Zelmid, respectivamente (dois medicamentos responsáveis pela inibição seletiva da recaptação da serotonina, indicados para o tratamento da depressão, do transtorno obsessivo-compulsivo e da bulimia nervosa).

Após a discussão na qual os alunos deveriam justificar a escolha feita, o projeto proposto foi estudar a estrutura eletrônica destes compostos com propriedades antidepressivas.

Cada aula teórica foi sucedida por aula prática, onde os alunos utilizaram os programas computacionais mais empregados em Química Quântica. Os alunos construíram as moléculas de Fluoxetina e Zimeldina no programa HyperChem ${ }^{16}$. As geometrias foram submetidas a uma análise conformacional visando buscar a estrutura de menor energia com o programa ChemPlus ${ }^{20}$. Posteriormente, estas 
a)

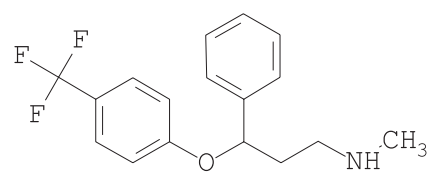

b)

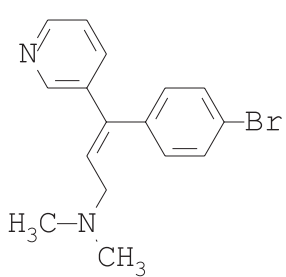

c)

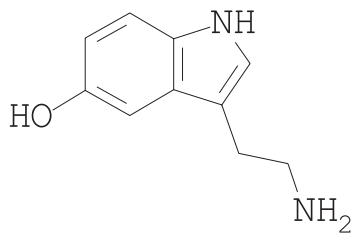

Figura 1. Estrutura dos compostos (a) Fluoxetina, (b) Zimeldina e (c) Serotonina

estruturas foram reotimizadas no pacote computacional Ampac com o método semi-empírico AM121.

Durante estas etapas, foram retomadas as discussões das aulas teóricas sobre a importância da análise conformacional quando não se dispõe de dados experimentais (cristalográficos) das moléculas a serem estudadas. Para os cálculos das propriedades eletrônicas foram utilizados os programas Ampac e Spartan. Estes cálculos fornecem as propriedades mostradas na Tabela 2, por meio das quais os alunos podem fazer as análises necessárias ao entendimento do problema estudado.

Tabela 2. Propriedades eletrônicas obtidas pelos cálculos teóricos

\begin{tabular}{lll}
\hline Propriedades calculadas & Fluoxetina & Zimeldina \\
\hline Calor de formação $(\mathrm{kcal} / \mathrm{mol})$ & $-147,4304$ & 83,9312 \\
Energia eletrônica $(\mathrm{eV})$ & $-27387,2494$ & $-19940,4660$ \\
Energia do HOMO $(\mathrm{eV})$ & $-9,5730$ & $-9,1155$ \\
Energia do LUMO $(\mathrm{eV})$ & $-0,195$ & $-0,404$ \\
\hline
\end{tabular}

A partir dos resultados obtidos junto com os alunos, foram discutidas as possíveis relações entre as propriedades obtidas pelos cálculos teóricos e o mecanismo de ação antidepressiva apresentada pelos compostos estudados. Considerando que o mecanismo de ação da inibição da recaptação da serotonina pelos antidepressivos Fluoxetina e a Zimeldina não se encontra perfeitamente elucidado e, com base nas propriedades calculadas, algumas considerações sobre as principais características apresentadas pelos dois compostos estudados foram analisadas, levando à formulação das possíveis interações entre estes compostos e o receptor biológico.

Um exemplo das discussões geradas foi a visualização dos gráficos dos orbitais de fronteira HOMO e LUMO mostrados nas Figuras 2 e 3 e os mapas de potencial na Figura 4. A partir das Figuras 2 e 3 , foi possível observar as regiões envolvidas em um mecanismo de transferência de carga entre os compostos estudados e o receptor biológico. Dessa forma, se o composto estudado (Fluoxetina ou Zimeldina) interage com o receptor biológico doando um elétron, o gráfico do

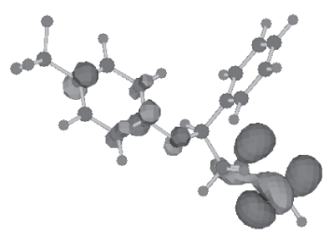

(a)

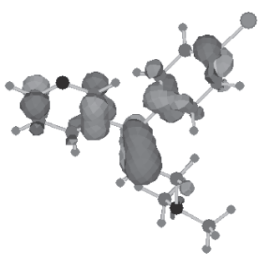

(b)
Figura 2. HOMO dos compostos estudados (a) Fluoxetina e (b) Zimeldina

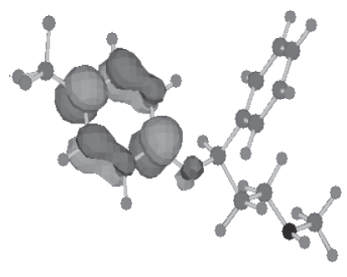

(a)

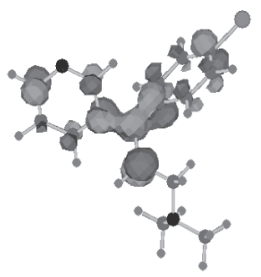

(b)
Figura 3. LUMO dos compostos estudados (a) Fluoxetina e (b) Zimeldina

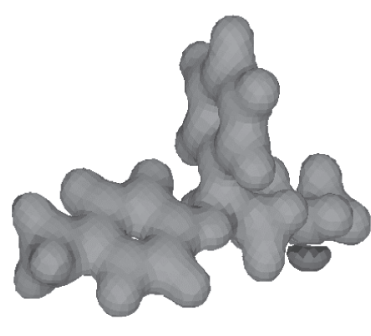

(a)

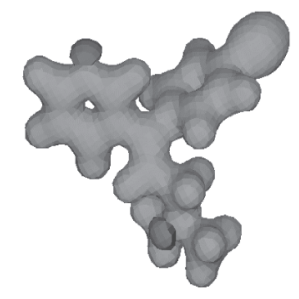

(b)
Figura 4. Mapa do potencial eletrostático dos compostos estudados (a) Fluoxetina e (b) Zimeldina

HOMO desse composto mostra a região mais provável de onde sairia o elétron. No caso da interação ocorrer com o composto recebendo um elétron do receptor, o gráfico do LUMO mostra a região mais provável do composto que receberia o elétron do receptor.

Após as discussões sobre os resultados, o grupo de alunos preparou uma apresentação para a classe, utilizando como recurso o PowerPoint. Esta apresentação gerou uma série de discussões e, assim, todos puderam participar da argüição. Essas discussões levaram os alunos a perceberem a complexidade envolvida nos mecanismos de ação biológica, uma vez que diversos fatores determinam as interações moleculares responsáveis pelos efeitos terapêuticos dos fármacos.

Para o caso dos compostos Fluoxetina e a Zimeldina, a existência de diferentes interações entre os compostos e o receptor biológico foi verificada pelos alunos com base na busca feita na literatura. Desta forma, puderam perceber a complexidade dos estudos envolvendo fármacos e receptores, uma vez que eles relataram que a Zimeldina, embora apresentando o mesmo efeito terapêutico da Fluoxetina, foi retirada do mercado por apresentar uma série de efeitos colaterais extremamente prejudiciais à saúde humana ${ }^{22}$.

\section{RESULTADOS E DISCUSSÃO}

Durante a etapa de introdução teórica, os alunos participaram ativamente das aulas teóricas e práticas com questionamentos. As inter- 
venções do professor ocorreram com o intuito de criar propostas de trabalho além da sala de aula, integrando o uso da biblioteca, periódicos e Internet. O trabalho desenvolvido em grupo se mostrou eficiente, uma vez que a diversidade de visões enriqueceu as discussões e os conflitos que surgiram fomentaram o exercício da autonomia e da responsabilidade do aluno perante sua própria aprendizagem.

Muitos alunos não tinham um entendimento dos motivos pelos quais determinados fármacos são capazes de atuar em mecanismos específicos, sendo responsáveis, por exemplo, por inibições enzimáticas que levam ao controle de doenças. Outro exemplo é o tão difundido conceito de "chave e fechadura" ${ }^{23}$, que para eles era mais um conceito sem significado, ou seja, eles não possuíam a compreensão de quais características (eletrônicas, energéticas, estruturais e/ou conformacionais) podem fazer com que uma "chave" sirva para determinada "fechadura", enquanto outra não.

A apresentação dos projetos e seus resultados por meio de seminários permitiu que os grupos socializassem seus conhecimentos e suas experiências durante as discussões. A divulgação dos resultados dessa forma é interessante por dar sentido à produção dos grupos, promovendo a auto-estima das pessoas e a valorização de suas realizações.

A opção de avaliação contínua foi importante para que ocorresse o replanejamento das atividades em função dos alunos e por respeitar a individualidade de cada um. Desta forma nota-se uma mudança de atitude por parte dos alunos que se envolvem mais no processo, uma vez que se sentem atuantes durante todo o processo e não apenas por sua produção final.

No questionário respondido ao final do curso, os alunos destacaram a relevância do tema, a importância de relacionar a teoria vista em aulas de química quântica com a prática da utilização dos programas, bem como a compreensão dos aspectos químicos envolvidos nos mecanismos de ação dos fármacos. De maneira geral, mostraram-se bastante satisfeitos com o curso, principalmente por terem a oportunidade de utilizar os programas computacionais e poderem visualizar os aspectos estruturais das moléculas, bem como as representações de orbitais moleculares e os mapas de potencial eletrostático. Os alunos demonstraram, ainda, compreensão de como a mecânica clássica e quântica resultam em diferentes modelos para representar moléculas, ligações e interações.

Além disso, a oportunidade de ver como essas ferramentas são utilizadas na pesquisa científica, bem como na resolução de problemas da indústria farmacêutica, motivou alguns alunos de pós-graduação, que também participaram do curso a aplicarem os conhecimentos adquiridos no desenvolvimento de suas teses (trabalhos), integrando seus resultados experimentais com os possíveis "insights" provenientes de cálculos teóricos.

\section{CONCLUSÃO}

A partir dos resultados obtidos, podemos sugerir que a realização desta atividade na forma de projeto é uma estratégia que pode ser bem sucedida devido à abordagem baseada em um tema atual, que desperta o interesse dos alunos e demonstra o alcance da teoria quântica e dos métodos computacionais na resolução de problemas químicos relevantes, como os que estão relacionados à Química Medicinal.
O curso possui um planejamento aberto e flexível que pode ser alterado ao longo de seu desenvolvimento. A concepção de conhecimento como produção coletiva torna a aprendizagem mais significativa, pois os alunos aprendem a utilizar seus conhecimentos para além da disciplina, relacionando-os com outras situações, tanto de outras especialidades da química quanto de temas da vida cotidiana. As atividades realizadas, com o computador na perspectiva de projetos, surgem como uma alternativa educacional visando atender às necessidades individuais dos estudantes, uma vez que a aprendizagem é fundamentalmente ativa, integrativa e reflexiva.

\section{AGRADECIMENTOS}

Os autores agradecem à Comissão de Cultura e Extensão do Instituto de Química de São Carlos e às agências CNPq, CAPES e FAPESP.

\section{REFERÊNCIAS}

1. Dias. J. J. C. T.; Química Quântica: Fundamentos e Métodos, Fundação Calouste Gulbenkian: Lisboa, 1982.

2. Morgon, N. H.; Quim. Nova 2001, 24, 676.

3. Ribeiro, A A; Greca, I. M.; Quim. Nova 2003, 26, 542.

4. http://www.qmc.ufsc.br/qmcweb/artigos/colaboracoes/informatica_ensino, acessada em Dezembro 2003.

5. Dewey, J.; Vida e Educação, 10ª ed., Melhoramentos: São Paulo, 1978.

6. Hernández, F.; Transgressão e Mudanças na Educação: os projetos de Trabalho, Art Med: Porto Alegre, 1998.

7. Levine, I. N.; Quantum Chemistry, 5a ed., Prentice-Hall: New Jersey, 2000.

8. Bunge, A. V.; Introdução à Química Quântica, Edgard Blücher: São Paulo, 1977.

9. Jensen, F.; Introduction to Computational Chemistry, Wiley: New York, 1999.

10. Höltje, H.; Molecular modeling: basic principles and applications, VCH: Weinheim, 1997.

11. Gans, W.; Amann A.; Boeyens, J. C. A.; Fundamental principles of molecular modeling, Plenum Press: New York, 1996.

12. Korolkovas, A.; Burchhalter, J. H.; Química Farmacêutica, Guanabara Dois: Rio de Janeiro, 1982.

13. Kubinyi, H.; QSAR: Hansch Analysis and Related Approaches, VCH: New York, 1993.

14. Sharaf, M. A.; Illman, D. L.; Kowalski, B. R.; Chemometrics, Wiley: New York, 1986.

15. Waterbeemd, H.; Chemometric Methods in Molecular Design, VCH: New York, 1995.

16. Ostlund, N. S.; HyperChem 4.5; Program for molecular visualization and simulation; University of Waterloo, Canada, 1995.

17. Hehre, W. J.; Huang, W. W.; Klunzinger, P. E.; Deppmeier, B. J.; Driessen, A. J.; Spartan 5.0; Program for molecular mechanics and quantum chemical calculations; University of California, USA, 1997.

18. Dewar, M. J. S.; AMPAC 6.5; Program for semiempirical calculations; University of Texas, USA, 1994.

19. Pople, J. A.; Gaussian 98; Program for semiempirical and ab initio calculations; Gaussian Inc., Pittsburgh, PA, 1998.

20. Ostlund, N. S.; ChemPlus 1.5: Extensions for HyperChem; University of Waterloo, Canada, 1994.

21. Dewar, M. J.; Zoebisch, E. G.; Healy, E. F.; Stewart, J. J. P.; J. Am. Chem. Soc. 1985, 107, 3902.

22. http://www.thedoctorwillseeyounow.com/articles/behavior/depressn_5/, acessada em Maio 2004.

23. Stryer, L.; Bioquímica, $4^{\mathrm{a}}$ ed., Guanabara Koogan: Rio de Janeiro, 1996. 